\title{
Research of Durability of Braille Formed in Paper
}

\author{
Volodymir MAYIK*, Taras DUDOK**, Edmundas KIBIRKŠTIS***, Ingrida VENYTE்**** \\ *Ukrainian Academy of Printing, Pidholosko 19, 79020 Lvov, Ukraine, E-mail: maik@uad.lviv.ua \\ **Ukrainian Academy of Printing, Pidholosko 19, 79020 Lvov, Ukraine, E-mail: j007@uad.lviv.ua \\ ***Kaunas University of Technology, Studentu 56, 51424 Kaunas, Lithuania, E-mail: edmundas.kibirkstis@ktu.lt \\ ****Kaunas University of Technology, Studenty 56, 51424 Kaunas, Lithuania, E-mail: ingrida.venyte@ktu.lt \\ crossref http://dx.doi.org/10.5755/j01.mech.25.1.20985
}

\section{Introduction}

Certain studies, e.g. a simulation of a Braille image longevity evaluation process by developing a digital control system of the conformity of parameters of Braille symbols with the representation of a model of factors affecting the quality of Braille in their active usage by the blind [1], are known. Furthermore, the influence of a superficial topography and friction on human perception is studied, because there is a presumption that superficial geometric peculiarities play an important role in perception [2], friction coefficients are analysed, analysis or study methods are suggested, wherein different types of surfaces may be correlated with friction and tactile response [3-7]. Moreover, there are studies on friction force of a finger with and without artificial sweat, friction coefficients of the humanoid finger on the acrylic, paper surface with/without the artificial sweat [8]. It is obvious that aforementioned and many other studies provide a capability to comprehend processes that occur during a human finger movement on a certain material [9], as well as demonstrate how to qualitatively measure, for example, the force of friction.

Another line of research includes modes of material processing for the purpose of obtaining relief images, $i$. e. Braille, or studying processes that take place in the material, where on a Braille is applied $[10,11]$.

However, the aforementioned studies do not an- swer the following question: how long will the Braille possess properties sufficient for being perceived by people with visual impairment? There is an obvious supposition that, during the friction process of a finger on a paper surface, where on a Braille is applied, (at least) lowering the height of a Braille dot will be evident. Our experiments carried out earlier demonstrate that such an effect is present [12].

The aim of the studies is to determine how the Braille applied onto ordinary paper by a Braille embosser will wear, and how the height of a Braille dot will change depending on the load (during storage in pallets, stacking, etc.).

In the present article, studies of the process of the change of height of a Braille dot taking into account factors that imitate not only the reading process but also factors that usually occur during use, storage and shipment of Braille have been expanded.

\section{Experiment equipment and method}

The Braille for the research was produced by a Braille embosser Index Braille Everest V2. Was used paper Volume Gloss: $80 \mathrm{~g} / \mathrm{m}^{2}, 90 \mathrm{~g} / \mathrm{m}^{2}, 105 \mathrm{~g} / \mathrm{m}^{2}, 115 \mathrm{~g} / \mathrm{m}^{2}, 130$ $\mathrm{g} / \mathrm{m}^{2}, 150 \mathrm{~g} / \mathrm{m}^{2}, 170 \mathrm{~g} / \mathrm{m}^{2}, 200 \mathrm{~g} / \mathrm{m}^{2}, 250 \mathrm{~g} / \mathrm{m}^{2}$ (Table 1). Before being embossed, all samples were covered by a laminating film, 24, 27, 50, 75 microns, on the "reading" side (Table 2, Fig. 2).

Table 1

Technical characteristics of coated paper Volume Gloss (Cezex)

\begin{tabular}{|c|c|c|c|c|c|c|}
\hline Grammage, $\mathrm{g} / \mathrm{m}^{2}$ & Thickness, $\mu \mathrm{m}$ & Density, $\mathrm{g} / \mathrm{cm}^{3}$ & Opacity, $\%$ & Brightness (ISO), $\%$ & Roughness, $\mu \mathrm{m}$ & Gloss, $\%$ \\
\hline 80 & 65 & 0.81 & 89 & 87 & 1.4 & 65 \\
\hline 90 & 73 & 0.81 & 91 & 87 & 1.4 & 65 \\
\hline 105 & 82 & 0.82 & 93 & 88 & 1.2 & 65 \\
\hline 115 & 96 & 0.83 & 95 & 88 & 1.2 & 65 \\
\hline 130 & 107 & 0.83 & 95 & 88 & 1.2 & 65 \\
\hline 150 & 130 & 0.87 & 96 & 88 & 1.4 & 6 \\
\hline 170 & 150 & 0.88 & 97 & 88 & 1.5 & 65 \\
\hline 200 & 180 & 0.90 & 98 & 88 & 1.5 & 65 \\
\hline 250 & 255 & 1.02 & 98 & 91 & 1.6 & 70 \\
\hline
\end{tabular}

Technical characteristics of films

Table 2

\begin{tabular}{|c|l|}
\hline Product name & \multicolumn{1}{c|}{ Main characteristics } \\
\hline Glossy film Cosmo & $\begin{array}{l}\text { Thickness - 24 } \mu \mathrm{m} \text {; Type - Gloss, 90\%; Structure: biaxially oriented polypropylene (BOPP) based, clear } \\
\text { and both side treated thermal laminating film. }\end{array}$ \\
\hline Matted film Cosmo & $\begin{array}{l}\text { Thickness }-27 \mu \mathrm{m} \text {; Type - Matt , 70-75\%; Structure: biaxially oriented polypropylene (BOPP) based, one } \\
\text { side matte and both side treated thermal laminating film. }\end{array}$ \\
\hline Hot Melt Gloss & Thickness - 50 $\mu \mathrm{m}$; Type - Gloss; Structure: polyethylene terephthalate (PET) based. \\
\hline Royal Sovereign & $\begin{array}{l}\text { Thickness - 75 } \mu \mathrm{m} \text {; Type - Gloss; Structure: polyethylene terephthalate (PET), low density polyethylene } \\
\text { (LDPE), ethylene vinyl acetate (EVA). }\end{array}$ \\
\hline
\end{tabular}


Coating with a laminating film aimed at two things. The first aim was: during the application of a Braille with a Braille embosser, not infrequently "breaks" occur (Fig. 1). These "breaks" obviously are poorly tactilely perceived, and a laminating film aids in eliminating this issue. Secondly, this operation also contributes to a longer service life, due to the paper not being affected by sweat, dirt, etc.

Apart from the laminating film, a page with Braille was also coated with a layer of acrylic paint (the reverse side) (Fig. 2).

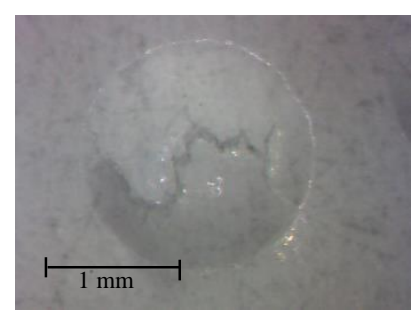

$\mathrm{a}$

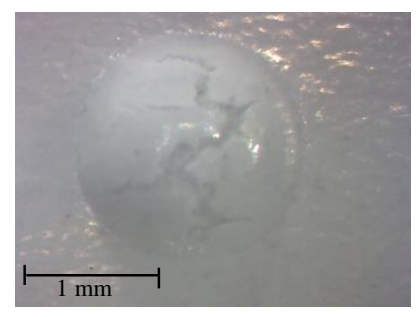

c

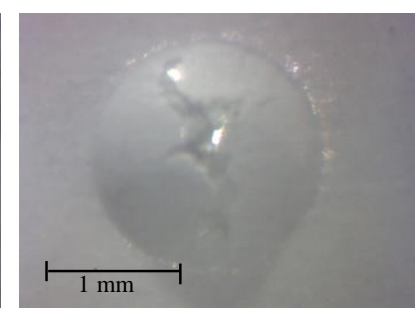

b

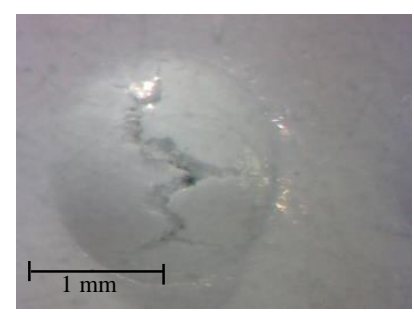

d
Fig. 1 Digital images of Braille dot on paper Volume Gloss: $\mathrm{a}-80 \mathrm{~g} / \mathrm{m}^{2} ; \mathrm{b}-115 \mathrm{~g} / \mathrm{m}^{2} ; \mathrm{c}-150 \mathrm{~g} / \mathrm{m}^{2} ; \mathrm{d}-250 \mathrm{~g} / \mathrm{m}^{2}$

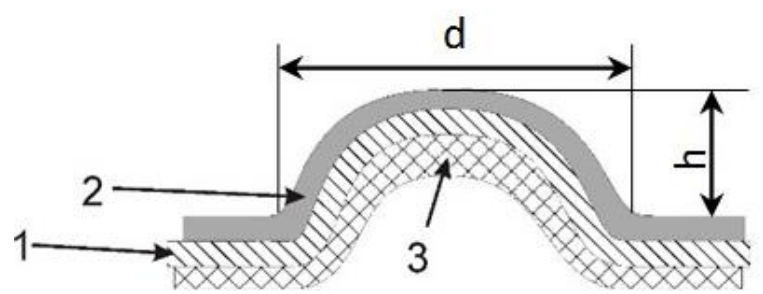

Fig. 2 Profile view of Braille dot : 1 - paper; 2 - laminating film; 3 - layer of acrylic ink; $h$ - Braille dot height; $d$ - Braille dot diameter

For the purpose of the research of the wear of a Braille, an original device was manufactured: a working tool - a leather cylinder, $1.5 \mathrm{~cm}$ in diameter, that moved on a sample in segments, one line of Braille each. The height of a Braille dot was measured every 500 cycles. The pressure was $1.0 \mathrm{~N}$.

The following paper samples were employed for the research: $115,130,150 \mathrm{~g} / \mathrm{m}^{2}$. As an option, 80, 90, 105, $170,200,250 \mathrm{~g} / \mathrm{m}^{2}$ were also used, but $80,90,105 \mathrm{~g} / \mathrm{m}^{2}$ presented as a poor choice, because paper breaks, even under lamination, had a poor appearance, it is non-aesthetic, and $200,250 \mathrm{~g} / \mathrm{m}^{2}-$ small height with lamination of 50 or 75 microns.

Small loads were left on an element of the script, and its settlement was examined with periodical contactless measurements of its height. The device FAG BRAI ${ }^{3}$ Braille Dot Checker was employed for the study of the change in height of a Braille dots.

\section{Results and discussion}

The dependence of Braille dot diameter from paper grammage and thickness of a laminating film is presented in Figs. 3 and 4.

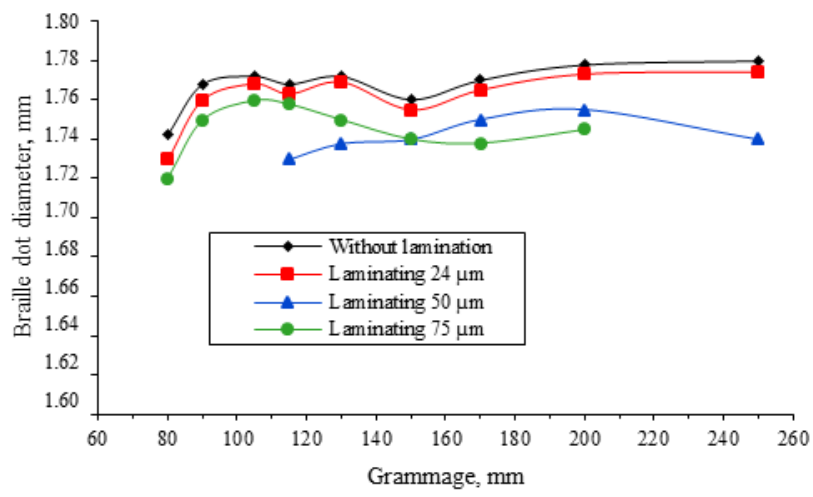

Fig. 3 The dependence of the diameter of the basis of a Braille dot from the paper grammage and the thickness of a laminating film

If the paper grammage is higher Braille dot diameter increases (see Fig. 3). Braille dot diameter also depends on the thickness of laminating film. If there is no film, the largest Braille dot diameter is obtained. When the laminating film is of a higher thickness, the Braille dot diameter is lower.

Table 3

The height of the Braille dot ( $\mathrm{mm}$ ) formed on different paper grammage and strengthening

\begin{tabular}{|c|c|c|c|c|}
\hline $\begin{array}{c}\text { Grammage, } \\
\mathrm{g} / \mathrm{m}^{2}\end{array}$ & $\begin{array}{c}\text { Without la- } \\
\text { minating } \\
\text { film }\end{array}$ & $\begin{array}{c}\text { Laminating } \\
\text { film } 24 \mu \mathrm{m}\end{array}$ & $\begin{array}{c}\text { Laminating } \\
\text { film } 50 \mu \mathrm{m}\end{array}$ & $\begin{array}{c}\text { Laminating } \\
\text { film } 75 \mu \mathrm{m}\end{array}$ \\
\hline 80 & 0.246 & 0.314 & 0.267 & 0.258 \\
\hline 90 & 0.339 & 0.301 & 0.270 & 0.258 \\
\hline 105 & 0.348 & 0.277 & 0.263 & 0.249 \\
\hline 115 & 0.344 & 0.289 & 0.264 & 0.255 \\
\hline 130 & 0.364 & 0.313 & 0.278 & 0.241 \\
\hline 150 & 0.360 & 0.283 & 0.289 & 0.248 \\
\hline 170 & 0.326 & 0.331 & 0.243 & 0.236 \\
\hline 200 & 0.342 & 0.273 & 0.183 & 0.198 \\
\hline 250 & 0.361 & 0.303 & 0.205 & -- \\
\hline
\end{tabular}

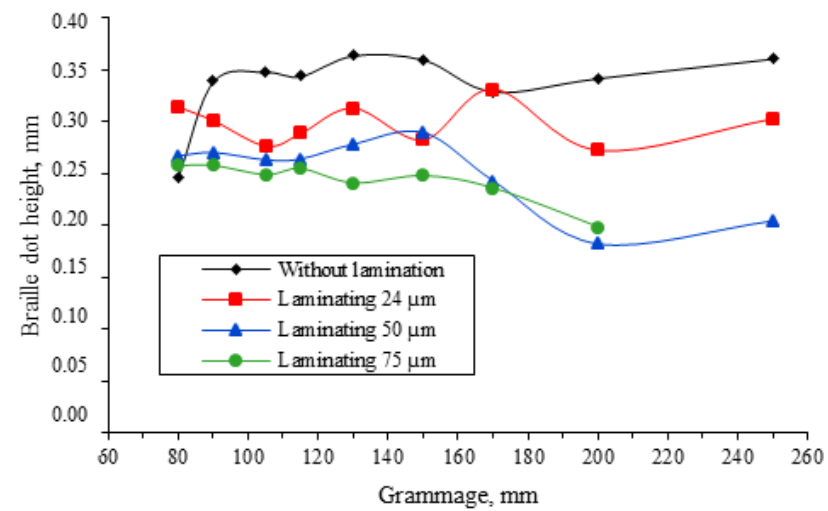

Fig. 4 The dependence of the height of the Braille dot from the paper grammage and thickness of a laminating film 
Fig. 4 and Table 3 show that in presence of $90 \mathrm{~g} / \mathrm{m}^{2}$ and higher paper grammage and the absence of laminating film, Braille dot is at its maximum height.

Braille dot attrition research disclosed its dependency on attrition cycles. Braille dot height reduction's dependence on the layer of laminating film and acrylic ink has also been researched. The results are delivered in Figs. 5-9. As it might be seen from Fig. 5, covering samples with acrylic ink affects their resistance to attrition. In cases without acrylic ink, Braille dot height decreased at greater extend. Respectively, when samples were covered with a layer of acrylic ink, Braille dot height was higher by 30-50\%.

The results presented in Fig. 6 disclose that Braille dot height reduction increased under higher number of wear cycles. This tendency is especially obvious from $2000 \mathrm{cy}-$ cles; when paper grammage is lower, Braille dot height reduction slows down.

Fig. 7 shows that the higher paper grammage, the smaller reduction of Braille dot height. Respectively, the higher paper grammage, the smaller number of cycles is needed to obtain Braille dot height stability.

Using a laminating film of 50 and $75 \mu \mathrm{m}$, when the number of attrition cycles is from 2000, Braille dot height reduction does not change (Figs. 8 and 9).

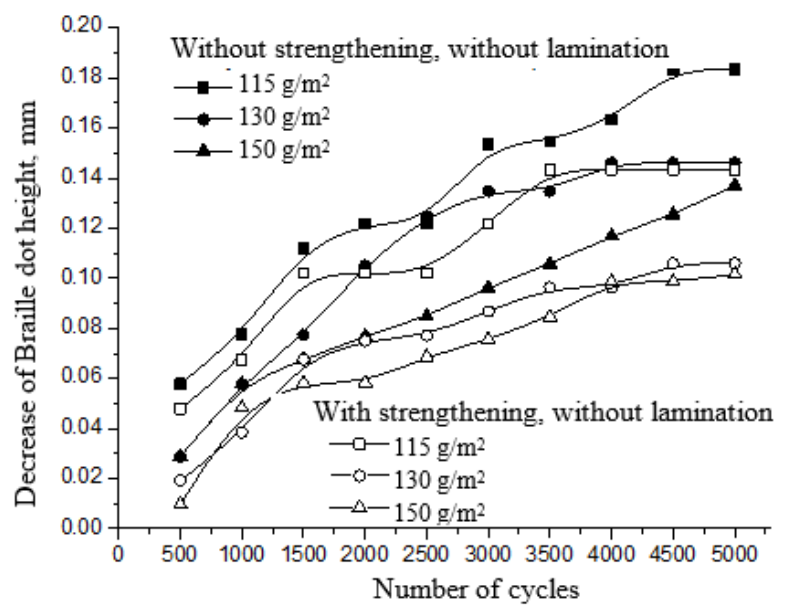

Fig. 5 The dependence of the lowering of the height of the Braille dot from the number of wear cycles without lamination and with/ without strengthening. Load force $-1.0 \mathrm{~N}$

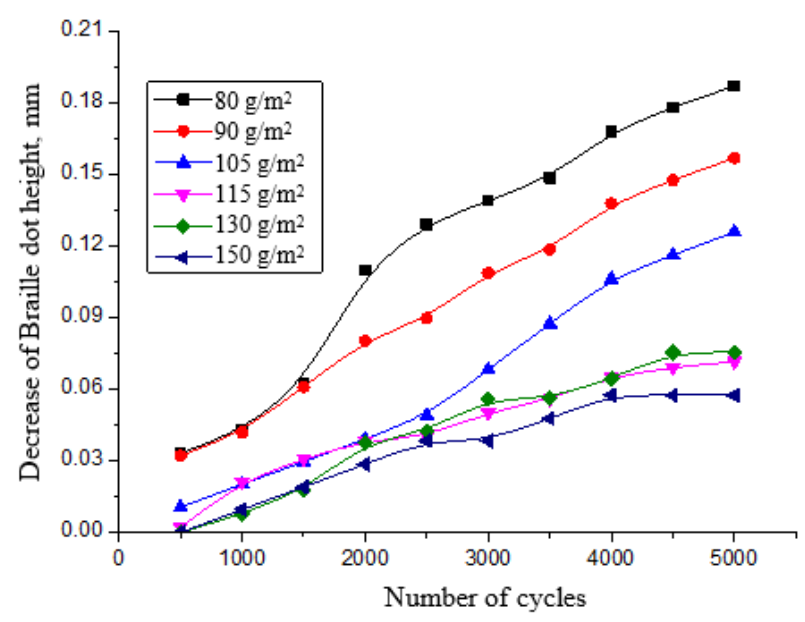

Fig. 6 The dependence of the lowering of the height of the Braille dot from the number of wear cycles with lamination and strengthening, the laminating film $24 \mathrm{mi}-$ crons. Load force $-1.0 \mathrm{~N}$

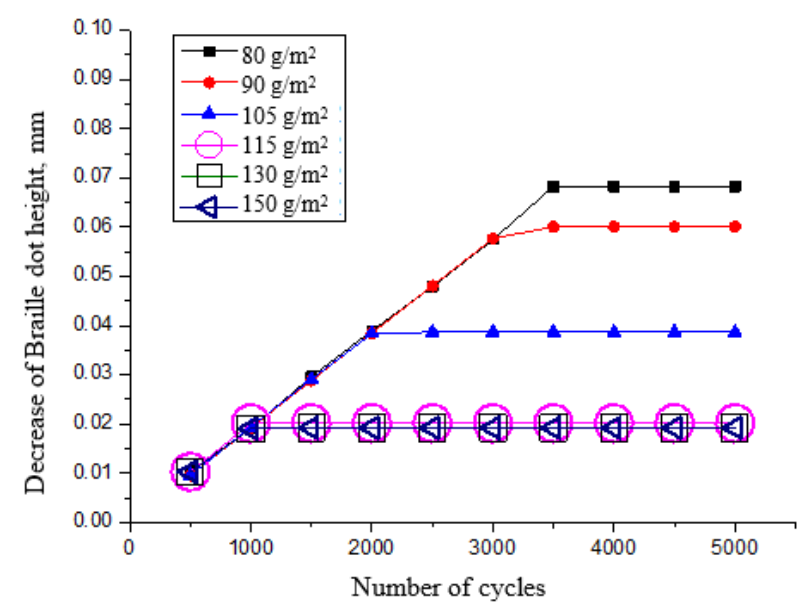

Fig. 7 The dependence of the lowering of the height of the Braille dot from the number of wear cycles with lamination and strengthening, the laminating film $27 \mathrm{mi}-$ crons. Load force $-1.0 \mathrm{~N}$

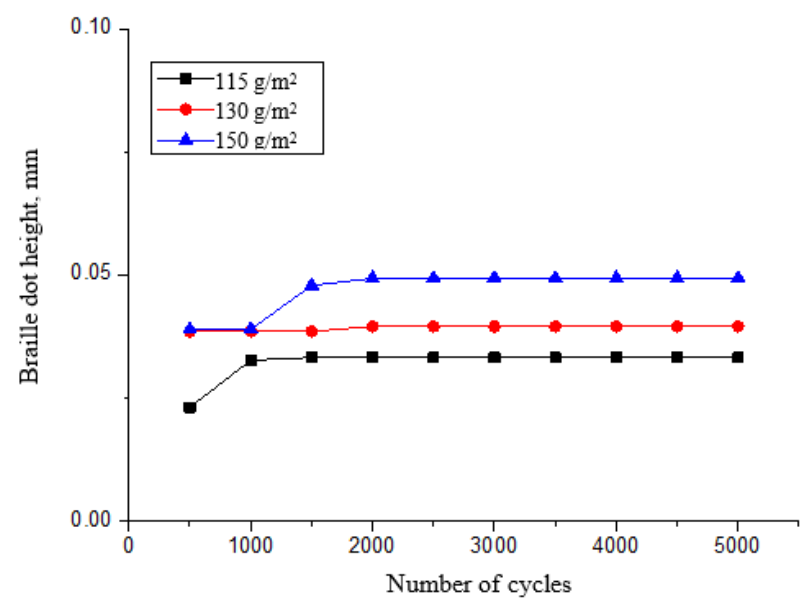

Fig. 8 The dependence of the lowering of the height of the Braille dot from the number of wear cycles with lamination and strengthening, the laminating film $50 \mathrm{mi}-$ crons. Load force $-1.0 \mathrm{~N}$

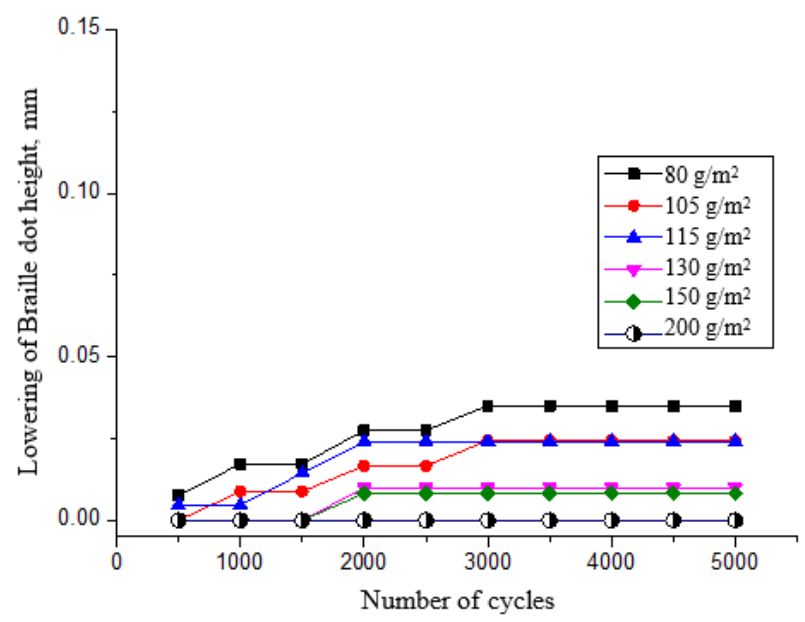

Fig. 9 The dependence of the lowering of the height of the Braille dot from the number of wear cycles with lamination and strengthening, the laminating film $75 \mathrm{mi}-$ crons. Load force $-1.0 \mathrm{~N}$

Braille dot height changes under different loads $(0.1 \mathrm{~N}, 0.2 \mathrm{~N}, 0.5 \mathrm{~N}, 1.0 \mathrm{~N})$ and times of effect are presented in Figs. 10-12. 


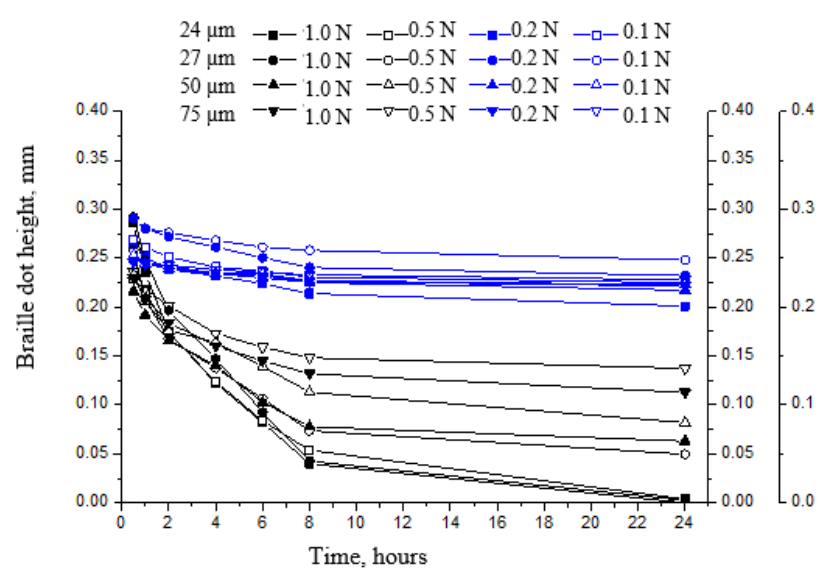

Fig. 10 The remaining height $(\mathrm{mm})$ of the Braille dot of the load action time for $115 \mathrm{~g} / \mathrm{m}^{2}$ paper with a laminating coating

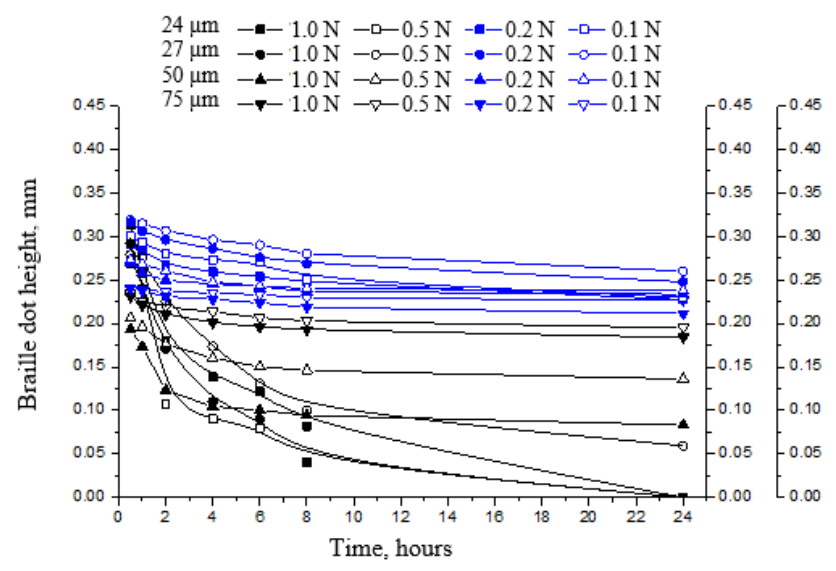

Fig. 11 The remaining height $(\mathrm{mm})$ of the Braille dot of the load action time for $130 \mathrm{~g} / \mathrm{m}^{2}$ paper with a laminating coating

It might be noticed that when Braille is made on a paper with grammages $115 \mathrm{~g} / \mathrm{m}^{2}, 130 \mathrm{~g} / \mathrm{m}^{2}, 150 \mathrm{~g} / \mathrm{m}^{2}$ and covered with different layers of a laminating film, Braille dot height decreased under short-term (up to $30 \mathrm{~min}$ ) loads of $1.0 \mathrm{~N}$ or $0.5 \mathrm{~N}$ (Fig. 10-12). When samples are affected longer time period (up to 24 hours) with a load of $0.1 \mathrm{~N}$, Braille dot height changes no more than $0.05 \mathrm{~mm}$ and with a load of $0.2 \mathrm{~N} \mathrm{~mm}$ it changes $0.09 \mathrm{~mm}$.

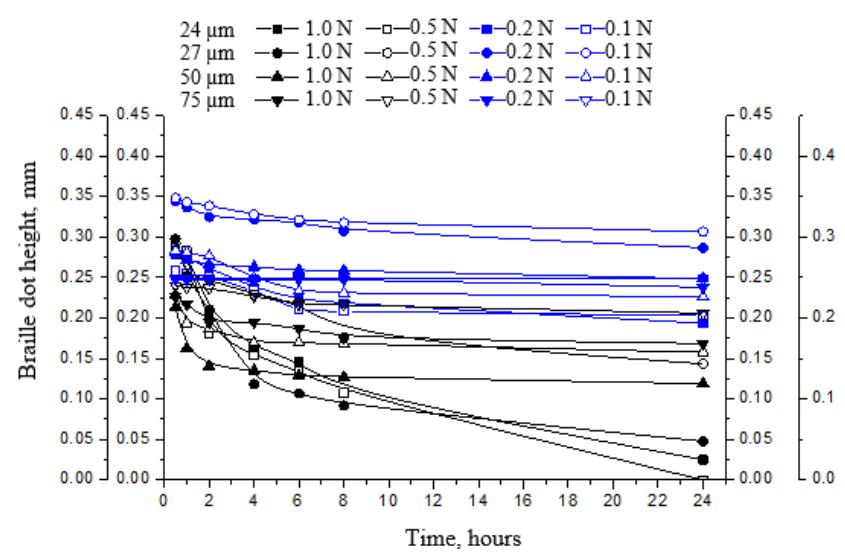

Fig. 12 The remaining height $(\mathrm{mm})$ of the Braille dot of the load action time for $150 \mathrm{~g} / \mathrm{m}^{2}$ paper with a laminating coating

\section{Conclusions}

Strengthening by a polymer layer after producing a Braille by a Braille embosser has a positive effect on a wear resistance, due to the height after 500 cycles (e.g. for $115 \mathrm{~g} / \mathrm{m}^{2}$ paper) without strengthening being lowered by 58 microns, and with strengthening by 48 microns. It is corresponding 29 and 19 microns for $130 \mathrm{~g} / \mathrm{m}^{2}$ paper. After 2500 cycles, these same numbers are 122 microns without strengthening and 101 microns with strengthening for $115 \mathrm{~g} / \mathrm{m}^{2}$ paper.

On the other hand, one of the conclusions of the analysis is the following: a strengthened structure demonstrates an equivalent drop of height after 3000 cycles, as a non-strengthened one after 2000 cycles, i. e. a positive effect is present.

Unacceptable changes (more than 50 microns) of a Braille dot height for $115 \mathrm{~g} / \mathrm{m}^{2}$ paper with a strengthening polymer layer and laminated films occur even with a shorttime load (less than $30 \mathrm{~min}$ ) weighting $1.0 \mathrm{~N}$ or $10.5 \mathrm{~N}$ in all samples without exception. For other samples (with loads weighting $0.1 \mathrm{~N}$ and $0.2 \mathrm{~N}$. For laminating films from the whole thickness range), even with a long-term load, a height changes not exceeding 0.09 microns is observed.

Analogous conclusions may be formulated regarding all types of paper $\left(130 \mathrm{~g} / \mathrm{m}^{2}, 150 \mathrm{~g} / \mathrm{m}^{2}\right)$ and laminating films.

\section{References}

1. Havenko, S.; Havenko, M.; Labetska, M. 2016. Simulation of durability the evaluation of relief-dot Braille images, Journal of Graphic Engineering and Design 7 (1): 27-30.

2. Liu, X.; Yue, Z.; Cai, Z.; Chetwynd, D. G.; Smith, S.T. 2008. Quantifying touch-feel perception: tribological aspects, Measurement Science and Technology 19(8): 084007.

3. Kim, M. S.; Kim, I. Y.; Park, Y. K.; Lee, Y. Z. 2013. The friction measurement between finger skin and material surfaces, Wear 301: 338-342.

4. Veijgen, N. K.; Masen, M. A.; Heide, E. 2012. A novel approach to measuring the frictional behaviour of human skin in vivo, Tribology International 54: 38-41.

5. Sivamani, R. K.; Goodman, J.; Norm, V.; Gitis, N. V.; Maibach, H. I. 2003. Friction coefficient to skin in real-time, Skin Research and Technology 9: 235-239.

6. Van Kuilenburg, J.; Masen, M. A.; Groenendijk, M. N.; Bana, V.; Van der Heide, E. 2012. An experimental study on the relation between surface texture and tactile friction, Tribology International 48: 15-21.

7. Julien Van Kuilenburg, J.; Marc A. Masen, MA.; Emile Van der Heide, E. 2012. A mechanistic approach to predicting the friction behaviour of human skin, ASME/STLE 2012 International Joint Tribology Conference: 45-47. http://dx.doi.org/10.1115/IJTC2012-61164.

8. Tomimoto, M. 2014. Artificial sweat for humanoid finger, Journal of Bionic Engineering 11: 98-108.

9. Klöcker, A.; Wiertlewski, M.; Théate, V.; Hayward, V.; Thonnard, J-L. 2013. Physical factors influencing pleasant touch during tactile exploration, PLoS ONE 8(11): e79085.

http://doi: 10.1371/journal.pone.0079085. 
10. Graeme, D.; Robinson, D.; Weston, A.; Whitakker, J.; Wilkins, S. M. 2009. An investigation of the height of embossed Braille dots for labels on pharmaceutical products, Journal of Visual Impairment and Blindness 103(10): 662-667.

11. Motyka, M. 2009. Research of influence of technological factors on height of elements of Braille's font, Printing Future days: 147-151.

12. Venytė, I.; Kibirkštis, E.; Mayik, V.; Dudok, T.; Vasylkiv, Y. 2014. Investigation of resistance to mechanical effect of Braille formed on different materials, Materials science 20(2): 183-188.
V. Mayik, T. Dudok, E. Kibirkštis, I. Venytè

RESEARCH OF DURABILITY OF BRAILLE FORMED IN PAPER

S u m m a r y

In the present work, the change of the height of a Braille dot is studied by imitating the usage process of a Braille. An analysis of the change of a Braille dot under a load action that occurs (or may occur) during storage in pallets, stocking, transportation, as well as actual use is performed. A simple Braille strengthening technology is suggested.

Keywords: Braille, durability of Braille dots, properties of paper.

Received June 18, 2018

Accepted January 15, 2019 